\title{
Risk of pregnancy and external validity in clinical trials of emergency contraception
}

Elizabeth Westley, Alison Bigrigg, Anne Webb, Sue Haskell, Kelly Blanchard, Becca Loftus-Granberg, Annik Sorhaindo, Karen Johnston, Aileen Spiers, Katrina Abuabara, Charlotte Ellertson

\section{Abstract}

Objectives To compare women who enrol in emergency contraception (EC) trials to those who decline and to understand why eligible women decline to participate.

Methods Data were collected from all women seeking EC ( $n=5787)$ at three clinics in the USA and UK during a period of nearly 1 year (from September 1997 to August 1998). The main outcome measures were pregnancy risk calculated by adjusted cycle day of ovulation.

Results Enrolled and non-enrolled women had similar mean ages and similar mean cycle lengths. However, the enrolled and non-enrolled groups were different with respect to adjusted cycle day of unprotected sexual intercourse (UPSI), the regularity of their cycles, recent hormone use, breastfeeding, the number of other acts of UPSI they had engaged in during the same cycle, and their willingness to participate in the study. Expected pregnancy risk among enrolled patients was higher than among nonenrolled EC seekers $(6.5 \%$ vs $5.0 \%, p<0.001$, calculated using Dixon conception probabilities, and $5.4 \%$ vs $4.6 \%$, $p=0.086$, calculated using Trussell conception probabilities). Unwillingness to take part in the study was the most common reason women did not enrol in the trial. Otherwise-eligible women most often declined to enrol because they were concerned about the effectiveness of the trial regimen.

Conclusions Women in EC trials are likely to face higher pregnancy risk than the general population. Clinical trials might overestimate the number of pregnancies averted by treatment because the number of expected pregnancies in trial populations is not representative of the population of all EC seekers. This information could be useful in projecting the public health impact of expanded EC access.

J Fam Plann Reprod Health Care 2006; 32(3): 165-169 (Accepted 24 February 2006)

Family Care International, New York, NY, USA

Elizabeth Westley, MPH, Co-ordinator, International Consortium for Emergency Contraception

The Sandyford Initiative, 2/6 Sandyford Place, Glasgow, UK Alison Bigrigg, FFFP, FRCOG, Director

Karen Johnston, RGN, BSc, Lead Nurse Base 75

Aileen Spiers, RM, BSc, Project Nurse

Abacus Centre for Contraception and Reproductive Health, Liverpool, UK

Anne Webb, MRCOG, MFFP, Consultant in Family Planning and Reproductive Health Care

Planned Parenthood of Greater lowa, Des Moines, IA, USA

Sue Haskell, DO, Medical Director

Becca Loftus-Granberg, Regional Director

Ibis Reproductive Health, Cambridge, MA, USA

Kelly Blanchard, MSc, President

Katrina Abuabara, MA, Consultant

Charlotte Ellertson, MPA, PhD, Founder and President

Population Council, Mexico City, Mexico

Annik Sorhaindo, MSc, Consultant

Correspondence to: Dr Kelly Blanchard, Ibis Reproductive Health, 2 Brattle Square, Cambridge, MA 02138-3742, USA.

Tel: +1 6173490040 . Fax: +16173490041.

E-mail: kblanchard@ibisreproductivehealth.org

\section{Key message points}

- Only $10 \%$ of all emergency contraception (EC) seekers at clinics during the study period were eligible to participate in the clinical trial, due to strict trial inclusion criteria. Concern about the effectiveness of the trial regimen was the most common reason that women who were otherwise eligible declined to participate.

- Women who enrolled in the clinical trial of EC were at a higher pregnancy risk than women who presented at the study clinics during the trial period but were not eligible to enrol in the trial.

- Data from EC trials might overestimate the number of pregnancies averted by treatment because the number of expected pregnancies in trial populations is not representative of the population of all EC seekers.

\section{Introduction}

Emergency contraception (EC) helps to prevent pregnancy after unprotected sexual intercourse (UPSI), and has the potential to reduce the incidence of unintended pregnancy and abortion. ${ }^{1}$ Methods include a regimen of ordinary combined oral contraceptive pills or progestin-only pills taken within 72-120 hours after UPSI, and insertion of a copper-releasing intrauterine device (IUD) within 5 days

A number of clinical trials have explored the safety 2,3 and efficacy ${ }^{4,5}$ of various EC regimens. Because there is consensus that the method is efficacious, placebo randomised trials are no longer ethical, and researchers must indirectly estimate the effectiveness of EC by comparing the pregnancy rates observed in a trial with expected pregnancy rates based on historic studies of women trying to conceive. We do not know of any studies that have evaluated the external validity of this method, namely the differences in pregnancy risk between women who enrol in EC clinical trials and EC users who do not. Our goal was to examine whether the conclusions drawn from trial populations are applicable to the general population of EC users. Additionally, analysis of the characteristics and reasoning of women seeking EC but not necessarily qualifying for or agreeing to join clinical trials of the method can aid us in interpreting the results of such trials, and can also aid in designing future trials.

Many EC clinical trials exclude women who have recently used or are currently using hormonal methods, whose cycles are so irregular that they might be anovulatory, or have engaged in more than one act of UPSI. Researchers do this to reduce the chances that women at little or no risk of pregnancy will join the study and dilute their ability to detect differences between different study regimens; limiting participation to women at highest pregnancy risk minimises the sample needed to show a difference between regimens and conserves scarce research resources. While this improves internal validity, it carries the risk that results will be less applicable to the larger population. The classic example of the 1954 US field trial of the Salk poliomyelitis vaccine illustrates the possibility for selection bias, even in a randomised design. Patients who refused to participate in the trial actually had much lower rates of paralytic polio than the control group due to prior exposure and build up of viral immunity. ${ }^{6}$ 


\section{ARTICLE}

The first question our study addressed is: Do women who enrol in EC clinical trials differ from those who do not, particularly with regard to their risk of pregnancy? Such data are required to accurately forecast the programme benefits of switching from one EC regimen to another with different effectiveness. If, for instance, $50 \%$ of typical EC seekers are actually already at no appreciable risk of pregnancy, then reducing their already negligible risk by $75 \%$ through giving them Yuzpe EC would avert nearly as many pregnancies as would giving them the possibly more effective but pricier levonorgestrel EC.

The second question our research addressed is: Why do otherwise-eligible women decline to participate in trials? We collected information on women's reasons for declining to join our clinical trial. If practical concerns, such as burdensome visit schedules, deter otherwise eligible women, study logistics could perhaps be streamlined to facilitate participation, saving recruitment costs and increasing external validity.

The EC literature contains much information on typical EC clients in the UK. In the USA, however, data are scarce. ${ }^{7}$ Our study provides a brief characterisation of EC clients from one site in the USA. Additional details regarding the difference between USA and UK users from this trial are published elsewhere. ${ }^{8}$

\section{Methods}

Working in both the USA and the UK, we fielded a large clinical trial of three modifications to the Yuzpe EC regimen, the details of which are described elsewhere. ${ }^{9}$ During the initial months of this study, from September 1997 to August 1998, we collected data from all women who came to the three original trial clinics (Glasgow, Liverpool and Iowa) seeking EC. We only enrolled women who met strict eligibility criteria: aged 16-45 years old (18-45 years at USA sites); had regular cycles (varying by no more than 3 days) between 21 and 35 days in length; arrived at the clinic within 120 hours after the first act of UPSI, which occurred between adjusted cycle Days 5 and 21 of the woman's current cycle; willing to abstain from further UPSI during the treatment cycle; and willing to keep a diary of side effects. We excluded women who had used any form of hormonal contraception in the past 2 months, or had not had two regular periods before arriving at the study clinic for EC. Finally, in order to enrol, women had to be available for follow-up and willing to take part in the study.

We compiled information from a number of instruments used in the larger study, including: a short checklist (completed by the clinic receptionists, non-study nurses or the client herself), a client interview using the structured eligibility questionnaire designed for the trial and/or a review of the woman's clinic chart. The total amount of data available for each woman varied. The data source, whether interview, checklist or chart review, had a significant impact on the data available (Table 1). In some cases the data collection instrument was not completed, for

Table 1 Data sources, by collection instrument and clinic location

$\begin{array}{ll}\text { Instruments } & \text { Eligibility questionnaire }(38 \%)^{\mathrm{a}} \\ (\% \text { of data from source) } & \text { Receptionist checklist }(36 \%)^{\mathrm{a}} \\ & \text { Checklist and chart review }(22 \%)^{\mathrm{a}} \\ & \text { Chart review }(4 \%)^{\mathrm{b}}\end{array}$

Clinic locations (dates) Iowa (September 1997-August 1998) Glasgow (September 1997-May 1998) Liverpool (October 1997-May 1998)

ancludes general information on emergency contraception (EC) seekers: age, cycle information and willingness to participate in the trial.

Includes general information on EC seekers: age and cycle information.

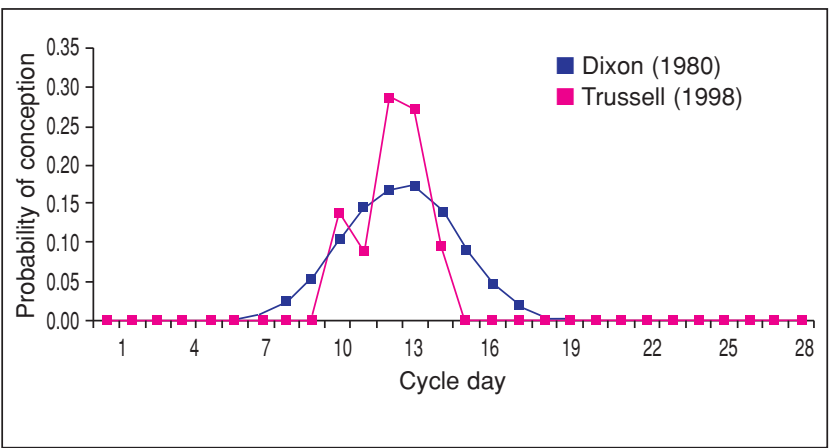

Figure 1 Conception probabilities by cycle day and method of calculation

example, when a woman was determined ineligible based on initial questions. Sample sizes are included in all tables to provide an indication of how much complete information was available for each analysis.

At the time we designed the clinical trial, researchers were using Dixon et al.'s method of assessing pregnancy risk. ${ }^{10}$ With this method, women are considered at risk of pregnancy if their adjusted cycle day of UPSI falls between the 5 th and 20th day of a 28-day cycle. For this analysis, we standardised women's reported cycle lengths to a 28-day cycle by subtracting the actual cycle length from 28 . To calculate the adjusted cycle day of UPSI, we added the standardised cycle length to the difference between the first day of the last period and the day of UPSI.

Dixon created a single set of conception probabilities by day of UPSI by combining data from several published studies. ${ }^{11-13}$ An error distribution was added to account for the biological variability of ovulation day. In EC trials, it is often not known exactly when ovulation occurs, as it is difficult to determine retrospectively.

Trussell et al.14 later published pregnancy risk estimates based on the North Carolina Early Pregnancy Study, a prospective cohort study conducted to determine the risk of early loss of pregnancy among healthy women. We used contraception probabilities for recognisable conceptions; these estimates do not include early pregnancy losses that were not likely to have been detected by the women themselves. We do not have good data to support which set of contraception probabilities might be more relevant for the population of women in our study, so we used both the classic Dixon method and newer Trussell estimates that have been employed in a number of EC efficacy calculations.4,5 Figure 1 shows the difference between the two sets of estimates.

The trial was originally designed to detect differences between treatment regimens and the overall power and sample size were determined based on those outcomes. ${ }^{9}$ For the purposes of this study, and based on what was logistically feasible, we simply collected data from all women seeking $\mathrm{EC}$ at the study clinics during the first 6 months of the trial recruitment period. A total of 5787 women visited the study clinics during this period, and we were able to collect data on the date of UPSI from 4372 women. This sample size gives us $95 \%$ power to detect a difference of $0.57 \%$ around an expected pregnancy risk of $5 \% .15$

We analysed data using the Statistical Package for the Social Sciences (SPSS ${ }^{\circledR}$, version 9.0; SPSS Inc., Chicago, IL, USA, 1999). Some women came to the study sites for EC more than once during the data collection period. In certain cases we analysed data by individual woman, and in others we analysed data by visit. We indicate the unit of analysis on all tables and use the term 'seekers' in cases where all data points were analysed and the term 'women' in cases where repeat visits were excluded. We coded and 
ARTICLE

\begin{tabular}{|c|c|c|c|c|c|c|c|c|}
\hline \multirow[t]{2}{*}{ Characteristic } & \multicolumn{2}{|l|}{ Glasgow, UK } & \multicolumn{2}{|l|}{ Liverpool, UK } & \multicolumn{2}{|l|}{ Iowa, USA } & \multicolumn{2}{|l|}{ Overall } \\
\hline & $\begin{array}{l}\text { Non-enrolled } \\
(n=3065)\end{array}$ & $\begin{array}{l}\text { Enrolled } \\
(n=255)\end{array}$ & $\begin{array}{l}\text { Non-enrolled } \\
(n=1402)\end{array}$ & $\begin{array}{l}\text { Enrolled } \\
(n=80)\end{array}$ & $\begin{array}{l}\text { Non-enrolled } \\
(n=522)\end{array}$ & $\begin{array}{l}\text { Enrolled } \\
(n=59)\end{array}$ & $\begin{array}{l}\text { Non-enrolled } \\
(n=4989)\end{array}$ & $\begin{array}{l}\text { Enrolled } \\
(n=394)\end{array}$ \\
\hline Age (mean, range) & $\begin{array}{l}23,13-50 \\
(n=394)\end{array}$ & $\begin{array}{l}24,16-43 \\
(n=3046)\end{array}$ & $\begin{array}{l}22,14-51 \\
(n=255)\end{array}$ & $\begin{array}{l}22,16-39 \\
(n=1390)\end{array}$ & $\begin{array}{l}21,13-43 \\
(n=80)\end{array}$ & $\begin{array}{l}22,18-37 \\
(n=515)\end{array}$ & $\begin{array}{l}22,13-51 \\
(n=59)\end{array}$ & $\begin{array}{l}24,16-43 \\
(n=4951)\end{array}$ \\
\hline $\begin{array}{l}\text { Cycle length } \\
\text { (mean, range) }\end{array}$ & $\begin{array}{l}28,14-150 \\
(n=2757)\end{array}$ & $\begin{array}{l}28,23-34 \\
(n=255)\end{array}$ & $\begin{array}{l}29,12-68 \\
(n=1158)\end{array}$ & $\begin{array}{l}28,25-32 \\
(n=80)\end{array}$ & $\begin{array}{l}29,15-90 \\
(n=467)\end{array}$ & $\begin{array}{l}28,24-34 \\
(n=59)\end{array}$ & $\begin{array}{l}28,12-150 \\
(n=4382)\end{array}$ & $\begin{array}{l}28,23-34 \\
(n=394)\end{array}$ \\
\hline $\begin{array}{l}\text { Adjusted day of UPSI } \\
\text { (mean, range) }\end{array}$ & $\begin{array}{l}15,1-28 \\
(n=2395)\end{array}$ & $\begin{array}{l}13,6-19 \\
(n=255)\end{array}$ & $\begin{array}{l}15,1-28 \\
(n=886)\end{array}$ & $\begin{array}{l}13,6-20 \\
(n=80)\end{array}$ & $\begin{array}{l}15,1-28 \\
(n=379)\end{array}$ & $\begin{array}{l}14,6-21 \\
(n=59)\end{array}$ & $\begin{array}{l}15,1-28 \\
(n=3660)\end{array}$ & $\begin{array}{l}13,6-21 \\
(n=394)\end{array}$ \\
\hline Regular cycles $(\%)^{\mathrm{a}, \mathrm{b}}$ & $\begin{array}{l}74.5 \\
(n=1383)\end{array}$ & $\begin{array}{l}100 \\
(n=255)\end{array}$ & $\begin{array}{l}61 \\
(n=895)\end{array}$ & $\begin{array}{l}100 \\
(n=80)\end{array}$ & $\begin{array}{l}70.8 \\
(n=476)\end{array}$ & $\begin{array}{l}100 \\
(n=59)\end{array}$ & $\begin{array}{l}69.5 \\
(n=2754)\end{array}$ & $\begin{array}{l}100 \\
(n=394)\end{array}$ \\
\hline Recent hormone use $(\%)^{\mathrm{a}, \mathrm{b}}$ & $\begin{array}{l}33.6 \\
(n=2923)\end{array}$ & $\begin{array}{l}0 \\
(n=255)\end{array}$ & $\begin{array}{l}36.7 \\
(n=1105)\end{array}$ & $\begin{array}{l}0 \\
(n=80)\end{array}$ & $\begin{array}{l}38.9 \\
(n=447)\end{array}$ & $\begin{array}{l}0 \\
(n=59)\end{array}$ & $\begin{array}{l}34.9 \\
(n=4475)\end{array}$ & $\begin{array}{l}0 \\
(n=394)\end{array}$ \\
\hline Breastfeeding $(\%)^{\mathrm{a}, \mathrm{b}}$ & $\begin{array}{l}0.5 \\
(n=1107)\end{array}$ & $\begin{array}{l}0 \\
(n=255)\end{array}$ & $\begin{array}{l}0 \\
(n=686)\end{array}$ & $\begin{array}{l}0 \\
(n=80)\end{array}$ & $\begin{array}{l}1.3 \\
(n=388)\end{array}$ & $\begin{array}{l}0 \\
(n=59)\end{array}$ & $\begin{array}{l}0.5 \\
(n=2181)\end{array}$ & $\begin{array}{l}0 \\
(n=394)\end{array}$ \\
\hline Other acts of UPSI $(\%)^{a, b}$ & $\begin{array}{l}3.5 \\
(n=1164)\end{array}$ & $\begin{array}{l}0 \\
(n=255)\end{array}$ & $\begin{array}{l}6.5 \\
(n=856)\end{array}$ & $\begin{array}{l}0 \\
(n=80)\end{array}$ & $\begin{array}{l}17.9 \\
(n=418)\end{array}$ & $\begin{array}{l}0 \\
(n=59)\end{array}$ & $\begin{array}{l}7.1 \\
(n=2438)\end{array}$ & $\begin{array}{l}0 \\
(n=394)\end{array}$ \\
\hline Willing to participate $(\%)^{\mathrm{a}, \mathrm{b}}$ & $\begin{array}{l}27.8 \\
(n=2988)\end{array}$ & $\begin{array}{l}100 \\
(n=255)\end{array}$ & $\begin{array}{l}25.3 \\
(n=1402)\end{array}$ & $\begin{array}{l}100 \\
(n=80)\end{array}$ & $\begin{array}{l}52.7 \\
(n=364)\end{array}$ & $\begin{array}{l}100 \\
(n=59)\end{array}$ & $\begin{array}{l}29.1 \\
(n=4678)\end{array}$ & $\begin{array}{l}100 \\
(n=392)\end{array}$ \\
\hline
\end{tabular}

The totals do not include multiple visits made by the same woman. ${ }^{a}$ Eligibility criteria for enrolment in clinical trial. ${ }^{b}$ Valid percentages (exclude missing values). UPSI, unprotected sexual intercourse.

analysed open-ended survey questions using standard methods of content analysis. Basic descriptive statistical analysis focused on differences between enrolled and nonenrolled study populations, including reasons for non-eligibility, lack of interest and pregnancy risk. To pair our data on pregnancy risk with the contraception estimates we assumed ovulation occurred on Day 14 of the adjusted cycle. We then calculated expected pregnancy risk among enrolled and non-enrolled EC seekers by summing the product of the number of reported acts of UPSI and the conception probability for each adjusted cycle day. The results were compared using two-sided Student's $t$-tests.

The Population Council Institutional Review Board approved the protocol for this study. In addition, the study was approved by relevant local ethical review committees at the study clinics.

\section{Results}

During the study period, 5383 women requested EC at 5787 visits to the study clinics. At the Glasgow site, 255

Table 3 Reasons emergency contraception seekers did not enrol in the clinical trial

\begin{tabular}{lllr}
\hline Reason & $\begin{array}{l}\text { Frequency } \\
(n)\end{array}$ & $\begin{array}{l}\text { Total } \\
(n)\end{array}$ & $\%$ \\
\hline Unwilling to participate in a study & 3565 & 5032 & 70.8 \\
Unwilling to keep a diary of side effects & 1217 & 1877 & 64.8 \\
Unwilling to come in for follow-up & 1103 & 1723 & 64.0 \\
Adjusted day of UPSI outside range & 1985 & 4553 & 43.6 \\
Hormone use in the last 2 months & 1836 & 4851 & 37.8 \\
Did not have two regular menstrual cycles & 892 & 2909 & 30.7 \\
Cycle length not between 21 and 35 days & 774 & 5011 & 15.4 \\
Unwilling to use barrier method until next & 175 & 1957 & 8.9 \\
menses & & & \\
Multiple acts of UPSI during study cycle & 189 & 2563 & 7.4 \\
Ageb & 276 & 5345 & 5.2 \\
Currently breastfeeding & 12 & 2295 & 0.5 \\
\hline
\end{tabular}

The total column refers to the number of data points available for each exclusion criterion. UPSI, unprotected sexual intercourse.

aParticipants excluded if act of UPSI did not occur between adjusted cycle Days 5 and 20.

bMinimum age for trial enrolment in UK was 16 years and in USA 18 years.
(7.7\%) women enrolled in the clinical trial, as did 80 $(5.4 \%)$ in Liverpool and $59(10.2 \%)$ in Iowa. Women who enrolled in the trial were approximately the same age and had approximately the same mean cycle length as those who did not enrol but, on average, non-enrolled women engaged in UPSI later in their cycles. As would be expected based on the trial exclusion criteria, non-enrolled women reported more irregular cycles, more recent hormone use, more breastfeeding and additional acts of UPSI during the study cycle (Table 2). Additional information on the differences between trial subpopulations has been published elsewhere. ${ }^{8}$

Due to strict inclusion criteria, only 559 of the EC seekers (i.e. $9.7 \%$ of the total) were eligible to participate in the clinical trial. Table 3 shows the amount of data available for each exclusion criterion and the most commonly recorded reasons EC seekers were not enrolled in the trial. As described in the Methods section, the amount of data available for each EC seeker varied depending on the data collection instrument used. If a woman was considered ineligible based on one criterion, additional information regarding other exclusion criteria may not have been recorded.

The majority of women $(73.0 \%)$ who were eligible enrolled in the clinical trial. There were 151 EC seekers

Table 4 Reasons otherwise-eligible emergency contraception seekers were not willing to join the trial

\begin{tabular}{ll}
\hline Reason & $\%(n=109)$ \\
\hline Concerned about effectiveness of trial regimen & 38.5 \\
Prefers regular hormonal EC regimen or IUD & 34.9 \\
Does not have time, not conducive to lifestyle & 14.7 \\
Anxious or worried & 8.3 \\
Does not want to be in the study & 7.3 \\
Against using EC & 5.5 \\
Unavailable for follow-up & 2.8 \\
Other & 0.9 \\
Took EC before & 0.0
\end{tabular}

Took EC before

The percentage figures refer to the ratio of replies to number of respondents. These figures do not total $100 \%$ as multiple responses were accepted. EC, emergency contraception; IUD, intrauterine device. 


\section{ARTICLE}

Table 5 Expected pregnancy rate among emergency contraception seekers, by trial enrolment and eligibility

\begin{tabular}{|c|c|c|c|c|c|}
\hline Conception probabilities $^{\mathrm{a}}$ & Total $(n)$ & Available data $(n)$ & Pregnancy risk $(\%)$ & $t$ value $^{\mathrm{d}}$ & Significance \\
\hline \multicolumn{6}{|l|}{ Dixon conception estimates $(1980)^{b}$} \\
\hline Enrolled & 408 & 408 & 6.46 & & \\
\hline Not enrolled: all women & 5379 & 3964 & 4.97 & -4.518 & $<0.001$ \\
\hline Not enrolled: UPSI between Days 5 and 21 & 3366 & 2958 & 6.66 & 0.603 & 0.547 \\
\hline Not enrolled: only eligible women & 559 & 137 & 8.24 & 2.933 & 0.004 \\
\hline \multicolumn{6}{|l|}{ Trussell conception estimates $(1996)^{c}$} \\
\hline Enrolled & 408 & 408 & 5.41 & & \\
\hline Not enrolled: all women & 5379 & 3964 & 4.60 & -1.718 & 0.086 \\
\hline Not enrolled: UPSI between Days 5 and 21 & 3366 & 2958 & 6.17 & 1.462 & 0.144 \\
\hline Not enrolled: only eligible women & 559 & 137 & 7.60 & 2.305 & 0.022 \\
\hline
\end{tabular}

${ }^{a}$ Assumed ovulation occurred on Day 14 . ${ }^{b}$ Weighted average. ${ }^{c}$ Includes only clinically recognisable pregnancies. ${ }^{\mathrm{d}}$ Two-sided $t$-tests comparing not enrolled to enrolled women's pregnancy risk. UPSI, unprotected sexual intercourse.

who met all the inclusion criteria for the trial except willingness to participate (i.e. $27 \%$ of those who would have been eligible for the trial did not enrol). These women were asked an open-ended question about why they did not care to participate. As shown in Table 4 for the 109 women for whom data were available, the most common reasons eligible women cited for not wanting to participate in the trial included concerns about the effectiveness of the trial regimen (39\% of respondents), preference for the 'standard' hormonal EC regimen or IUD (34\%), time or lifestyle constraints (15\%) and concerns about participating in the trial $(8 \%)$.

Over three-quarters $(77 \%)$ of all EC seekers engaged in UPSI between adjusted cycle Days 5 and 21 (Figure 2). Non-enrolled women as a group were at a lower risk of pregnancy based on cycle day than enrolled women because non-enrolled women had sex on days that carried little pregnancy risk (Table 5). The average expected pregnancy rate, calculated using the Dixon method, was $5.0 \%$ for non-enrolled women and $6.5 \%$ for enrolled women $(p<0.001)$. The average expected pregnancy rate using the Trussell conception probabilities was $4.6 \%$ for non-enrolled women and $5.4 \%$ for enrolled women $(p=$ 0.086 ).

We also compared the pregnancy risk of two subgroups of non-enrolled women to enrolled women. Non-enrolled women who had UPSI in the same Day 5-21 window had a similar pregnancy risk based on cycle day as enrolled women. All women who arrived at the clinic were offered EC, including those who had UPSI outside the Day 5-21 window. Unfortunately, we do not have information on the percentage of women not enrolled in the trial who actually

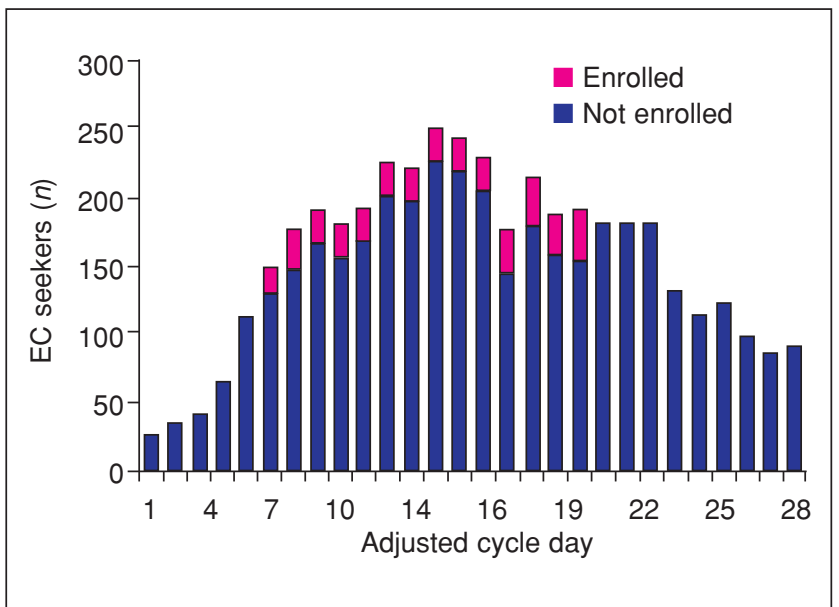

Figure 2 Adjusted cycle day of unprotected sexual intercourse among enrolled and non-enrolled emergency contraception (EC) seeker took the product, nor do we know the pregnancy outcomes. Eligible, but not enrolled women had a significantly higher pregnancy risk than those who enrolled in the trial. The most common reasons cited among these women for not enrolling in the trial included concerns about the effectiveness of the trial regimen and a preference for the regular regimen.

\section{Discussion}

Researchers usually express EC effectiveness as the 'prevented fraction' or proportion of pregnancies averted by treatment (i.e. 1 - observed pregnancies/expected pregnancies). Although we were unable to collect data on the number of observed pregnancies in the general population of all EC seekers to compare to the number of observed pregnancies in the trial, we can compare the number of expected pregnancies in each population. As described above, researchers typically calculate the number of expected pregnancies using reported cycle day of UPSI and conception probabilities. In our study, women enrolled in the clinical trial faced a 5.4-6.5\% risk of pregnancy, while women who did not enrol in our trial faced a 4.6-5.0\% risk of pregnancy. If EC has the same efficacy in both populations, we would expect treatment to reduce the number of expected pregnancies by the same fraction in both populations. If the expected pregnancy rate in the general population is smaller than the expected pregnancy rate in a clinical trial then the number of averted pregnancies will be smaller as well. Clinical trials may overestimate the number of pregnancies averted with increased access to EC. In fact, these results suggest that the general population of EC users is likely to have even lower rates of pregnancy than have been seen in clinical trials. Consequently the cost effectiveness of $\mathrm{EC}$ in the general population may be overestimated as well. ${ }^{16-20}$

Alternatively, non-enrolled women may be at higher risk of pregnancy than women in EC clinical trials because they are ineligible to enrol due to additional acts of UPSI in a cycle or because they decline to enrol, preferring a 'proven' EC regimen over an experimental regimen. In all randomised EC trials, as in our trial, enrolment is restricted to women who have only had one act of UPSI 72 (or 120) hours before they present at the clinic. Overall, $7.1 \%$ of the women of the women presenting at our study clinics reported acts of UPSI earlier in the cycle, in addition to the act of UPSI that led them to seek care. If women are using EC after only a proportion of acts of UPSI, they may not be significantly reducing their overall risk of unintended pregnancy, despite high efficacy of and good access to EC. Repeat use of EC for all acts of UPSI should be encouraged. 20

Our results also showed that eligible, but not enrolled women had a significantly higher pregnancy risk than those 
who enrolled in the trial. Concerns about effectiveness of the trial regimen or a preference for the regular regimen were the most common reasons these women cited for declining to participate in the trial. It is possible that these women declined to participate in the EC trial explicitly because they were at high risk and preferred a quick and proven treatment.

Finally, even studies such as the present one that look at all women presenting for EC at clinics (both those who enrol in clinical trials and those who do not) may not be sufficient to estimate the true population risk profile. A number of studies have shown that women are generally hesitant to request EC. ${ }^{22-24}$ Women who present for EC are already highly motivated to prevent pregnancy, and may not be representative of the population with the poorest access to contraception and most at risk of unintended pregnancy. Reaching higher-risk populations could show a greater reduction in unintended pregnancy than clinical trials predict.

There are few published data on the external validity of EC clinical trials. Our data are among the first to show that EC seekers are indeed at a lower risk of pregnancy than clinical trial data would suggest, and seekers themselves may be at a lower pregnancy risk than women in the general population. Therefore, overall measures of the public health impact of increased community access to EC, such as abortions or pregnancies adverted, may be difficult to predict and measure, and changes may require sustained interventions that reach potentially marginalised and higher-risk populations.

While calculations based on recall and conception probabilities appear to be the best method for calculating EC effectiveness, it is important to acknowledge the limitations of the data used. Our calculations assume that women accurately reported data on cycle regularity, date of last menstrual period and cycle day of intercourse, and that these factors accurately predict ovulation. We did not have complete data for all women who did not enrol in the trial, and recall bias may have influenced the data. ${ }^{25}$ Moreover, conception probabilities are derived from studies of women trying to conceive, and women who have experienced contraceptive failure may be at lower risk than women in the conception studies. ${ }^{26}$ The reported pregnancy risk estimates are based only on cycle day of UPSI and do not account for other factors that may affect pregnancy risk such as additional acts of UPSI, hormone use, breastfeeding and cycle irregularity. For any individual woman it is difficult to predict how the combination of these factors impacts her pregnancy risk. Finally, our clinical trial was unique in excluding women who had UPSI outside of cycle Days 5-21, which may limit the generalisability of our results.

We emphasise that our data do not provide any additional information about the efficacy of EC; these results are pertinent only for estimating the number of expected pregnancies in a population of EC seekers. EC has no contraindications and only a few transient side effects. Even when a woman's pregnancy risk may be low, we urge providers to offer information and support to help women assess whether they want EC.

Collecting data that allow for comparisons between study populations and the larger general population that is the likely target of future interventions should be included in clinical trials protocols wherever possible.

\section{Acknowledgements}

The authors wish to thank all the doctors, nurses, receptionists and patients without whom this study would not have been possible. The authors also thank James Trussell for his comments on drafts of this manuscript.
Statements on funding and competing interests

Funding. This study was funded by Mary Wohlford, John Snyder, the Open Society Institute, the David and Lucile Packard Foundation, the William and Flora Hewlett Foundation, the Population Council, and an anonymous donor.

Competing interests. None identified.

References

1 Trussell J, Stewart F, Guest F, Hatcher RA. Emergency contraceptive pills: a simple proposal to reduce unintended pregnancies. Fam Plann Perspect 1992; 24: 269-273.

2 Glasier A. Safety of emergency contraception. J Am Med Womens Assoc 1998; 53(Suppl. 2): 219-221.

3 Norris Turner A, Ellertson C. How safe is emergency contraception? Drug Saf 2002; 25: 695-706.

4 Cheng L, Gulmezoglu AM, Ezcurra E, Van Look PF. Interventions for emergency contraception. Cochrane Database Syst Rev 2000;(2):CD001324

5 von Hertzen $\mathrm{H}$, Piaggio G, Ding J, Chen J, Song S, Bartfai G, et al. Low dose mifepristone and two regimens of levonorgestrel for emergency contraception: a WHO multicentre randomised trial. Lancet 2002; 360: 1803-1810.

6 Meier P. The biggest health experiment ever: the 1954 field trial of the Salk poliomyelitis vaccine. In: Tanur JM (ed.), Statistics: A Guide to the Biological and Health Sciences. San Francisco, CA: Holden-Day Press, 1997.

7 Ellertson C, Shochet T, Blanchard K, Trussell J. Emergency contraception: a review of the programmatic and social science literature Contraception 2000; 61: 145-186.

8 Blanchard K, Haskell S, Ferden S, Johnstone K, Spears A, Evans M, et al. Differences between emergency contraception users in the United States and the United Kingdom. J Am Med Womens Assoc 2002; 57: 200-203, 214

9 Ellertson C, Webb A, Blanchard K, Bigrigg A, Haskell S, Shochet T, et al. Modifying the Yuzpe regimen of emergency contraception: a multicenter randomized controlled trial. Obstet Gynecol 2003; 101: $1160-1167$.

10 Dixon GE, Schlesselman JJ, Ory HW, Blyw RP. Ethinylestradiol and conjugated estrogens as postcoital contraceptives. JAMA 1980; 244: 1336-1339.

11 Barrett JC, Marshall J. The risk of conception on different days of the menstrual cycle. Popul Stud (Camb) 1969; 23: 455-461.

12 Schwartz D, Mayaux MJ, Martin-Boyce A, Czyglik F, David G. Donor insemination: conception rate according to cycle day in a series of 821 cycles with a single insemination. Fertil Steril 1979; 31: $226-229$.

13 Vollman RF. Assessment of the fertile and sterile phases of the menstrual cycle. Int Rev Nat Fam Plann 1977; 1: 40-47.

14 Trussell J, Rodríguez G, Ellertson, C. New estimates of the effectiveness of the Yuzpe regimen of emergency contraception. Contraception 1998; 57: 363-369.

15 Trussell J, Ellertson C, von Hertzen H, Bigrigg A, Webb A, Evans M, et al. Estimating the effectiveness of emergency contraceptive pills. Contraception 2003; 67: 259-265.

16 Trussell J, Koenig J, Ellertson C, Stewart F. Preventing unintended pregnancy: the cost-effectiveness of three methods of emergency contraception. Am J Public Health 1997: 87: 932-937.

17 Trussell J, Koenig J, Stewart F, Darroch JE. Medical care cost savings from adolescent contraceptive use. Fam Plann Perspect 1997; 29: 248-255, 295.

18 Trussell J, Wiebe E, Shochet T, Guilbert É. Cost savings from emergency contraceptive pills in Canada. Obstet Gynecol 2001; 97(5 Part 1): 789-793.

19 Trussell J, Shochet T. Cost-effectiveness of emergency contraceptive pills in the public sector in the USA. Expert Rev Pharmacoeconomics Outcomes Res 2003; 3: 433-440.

20 Trussell J, Calabretto H. Cost savings from use of emergency contraceptive pills in Australia. Aust N Z J Obstet Gynaecol 2005; 45: 308-311.

21 Abuabara K, Becker D, Ellertson C, Blanchard K, Schiavon R, Garcia SG. As often as needed: appropriate use of emergency contraceptive pills. Contraception 2004; 69: 339-342.

22 Fairhurst K, Ziebland S, Wyke S, Seaman P, Glasier A. Emergency contraception: why can't you give it away? Qualitative findings from an evaluation of advance provision of emergency contraception. Contraception 2004; 70: 25-29.

23 Gainer E, Blum J, Toverud EL, Portugal N, Tyden T, Nesheim BI, et al. Bringing emergency contraception over the counter: experiences of non-prescription users in France, Norway, Sweden and Portugal. Contraception 2003; 68: 117-124.

24 Free C, Lee RM, Ogden J. Young women's accounts of factors influencing their use and non-use of emergency contraception: indepth interview study. BMJ 2002; 325: 1393-1396.

25 Stirling A, Glasier A. Estimating the efficacy of emergency contraception - how reliable is the data? Contraception 2002; 66: $19-22$.

26 Raymond E, Taylor D, Trussell J, Steiner MJ. Minimum effectiveness of the levonorgestrel regimen of emergency contraception. Contraception 2004; 69: 79-81. 